\title{
Correction to: Explaining Why There is Something Rather than Nothing
}

\author{
Andrew Brenner ${ }^{1,2}$ \\ Published online: 20 August 2020 \\ (๑) Springer Nature B.V. 2020
}

\section{Correction to: Erkenntnis https://doi.org/10.1007/s10670-020-00277-6}

In the original publication of this article, we have missed to include second affiliation of the corresponding author in the online published article. Now the same has been provided in this correction.

Publisher's Note Springer Nature remains neutral with regard to jurisdictional claims in published maps and institutional affiliations.

The original article can be found online at https://doi.org/10.1007/s10670-020-00277-6.

Andrew Brenner

andrew.t.brenner@gmail.com

1 Department of Religion and Philosophy, Hong Kong Baptist University, 224 Waterloo Road, Kowloon Tong, KLN, Hong Kong

2 Department of Philosophy, Linguistics, Theory of Science, University of Gothenburg, PO Box 200, SE405 30 Gothenburg, Sweden 